Article

\title{
Efficient Preparation of Bafilomycin A1 from Marine Streptomyces lohii Fermentation Using Three-Phase Extraction and High-Speed Counter-Current Chromatography
}

\author{
Ye Yuan ${ }^{1,2}$, Xiaoping He ${ }^{1}$, Tingting Wang ${ }^{1}$, Xingwang Zhang ${ }^{3}$, Zhong Li ${ }^{4,5}$, Xiaoqing Xu ${ }^{6}$, \\ Weiyan Zhang ${ }^{1}$, Xiaojun Yan ${ }^{2, *} \mathbb{C}$, Shengying $\mathrm{Li}^{3, *}$ and Shan $\mathrm{He}^{1, * \mathbb{D}}$ \\ 1 Li Dak Sum Yip Yio Chin Kenneth Li Marine Biopharmaceutical Research Center, \\ College of Food and Pharmaceutical Sciences, Ningbo University, Ningbo 315800, China; \\ 23yuanye@163.com (Y.Y.); 18892628896@163.com (X.H.); 18251965896@163.com (T.W.); \\ zhangweiyan13@126.com (W.Z.) \\ 2 School of Marine Science, Ningbo University, Ningbo 315211, China \\ 3 State Key Laboratory of Microbial Technology, Shandong University, Qingdao 266237, China; \\ zhangxingwang@sdu.edu.cn \\ 4 Shandong Provincial Key Laboratory of Synthetic Biology, and CAS Key Laboratory of Biofuels \\ at Qingdao Institute of Bioenergy and Bioprocess Technology, Chinese Academy of Sciences, \\ Qingdao 266101, China; lizhong@qibebt.ac.cn \\ 5 University of Chinese Academy of Sciences, Beijing 100049, China \\ 6 Rushan Hanwei Biological Science and Technology Co., Ltd., Rushan 264502, China; xiaoqingxu@163.com \\ * Correspondence: yanxiaojun@nbu.edu.cn (X.Y.); lishengying@sdu.edu.cn (S.L.); heshan@nbu.edu.cn (S.H.); \\ Fax: +86-574-8760-0458 (X.Y.); +86-574-8760-4388 (S.H.)
}

Received: 4 June 2020; Accepted: 23 June 2020; Published: 25 June 2020

\begin{abstract}
An efficient strategy was developed for the rapid separation and enrichment of bafilomycin A1 (baf A1) from a crude extract of the marine microorganism Streptomyces lohii fermentation. This strategy comprises liquid-liquid extraction (LLE) with a three-phase solvent system ( $n$-hexane-ethyl acetate-acetonitrile-water $=7: 3: 5: 5, v / v / v / v)$ followed by separation using high-speed counter-current chromatography (HSCCC). The results showed that a $480.2-\mathrm{mg}$ fraction of baf A1-enriched extract in the middle phase of the three-phase solvent system was prepared from 4.9 g of crude extract after two consecutive one-step operations. Over $99 \%$ of soybean oil, the main hydrophobic waste in the crude extract, and the majority of hydrophilic impurities were distributed in the upper and lower phase, respectively. HSCCC was used with a two-phase solvent system composed of $n$-hexane-acetonitrile-water $(15: 8: 12, v / v / v)$ to isolate and purify baf A1 from the middle phase fraction, which yielded $77.4 \mathrm{mg}$ of baf A1 with $>95 \%$ purity within $90 \mathrm{~min}$. The overall recovery of baf A1 in the process was determined to be $95.7 \%$. The use of a three-phase solvent system represents a novel strategy for the simultaneous removal of hydrophobic oil and hydrophilic impurities from a microbial fermentation extract.
\end{abstract}

Keywords: three-phase solvent system; oil removal; liquid-liquid extraction; bafilomycin; HSCCC

\section{Introduction}

Bafilomycin A1 (baf A1) is a 16-membered ring macrolide antibiotic that was first isolated from Streptomyces griseus in 1983 [1,2]. Baf A1 was previously reported to show antimicrobial, antiosteoporosis, and anticancer activities [3-5]. In particular, baf A1 is potential agent for the treatment of osteoporosis and tumors, because it is an effective inhibitor of both vacuolar $\mathrm{H}^{+}$-ATPase (V-ATPase) [3] 
and sarco/endoplasmic reticulum $\mathrm{Ca}^{2+}$-ATPase (SERCA) pumps [6]. However, baf A1 was restricted from becoming a clinical drug due to its marked toxicity to mammalian cells [4]. To lower the toxicity and optimize the pharmacological properties through medicinal chemistry approaches for further drug development, the cost-effective generation of the structurally complex baf A1 supply is important, even though continued efforts on the total synthesis and semi-synthesis of bafilomycin derivatives were made [7-9].

In our previous study, a mutant strain marine Streptomyces lohii orf $2 \& 3$ was shown to overproduce baf A1 under optimized culture conditions. During cultivation, this mutant strain required an abundant a feedstock of soybean oil $(60 \mathrm{~g} / \mathrm{L})[10]$ to be used as a long-term carbon source and a fast polyketide precursor. However, the presence of excess soybean oil complicated the following purification process after it was extracted with organic solvents alongside baf A1 and some other produced natural products from the culture.

As a conventional isolation method, liquid-liquid extraction (LLE) is widely used in crude sample pretreatment due to its low cost, high efficiency, and simple procedure [11,12]. However, the low precision of this method often limits its utility in natural product isolation. In recent years, three-phase solvent systems were successfully applied to the separation of multiple component mixtures with a wide range of hydrophobicity [13-19]. In principle, a three-phase solvent system is able to form three immiscible phases after settling, consisting of a hydrophobic upper phase (UP), a moderately polar middle phase (MP), and a hydrophilic lower phase (LP) [13]. During extraction, hydrophobic components (such as fatty acids) and hydrophilic ones (such as saccharide, protein) can be well distributed in the UP and LP, respectively [14,15], while intermediate-polarity and drug-like natural products would be enriched in the MP. This method accordingly holds great potential for isolating target molecules from a complex mixture in an efficient manner. To date, several three-phase solvent systems were reported for complex sample pretreatment and further chromatographic isolation, including $n$-hexane-methyl acetate-acetonitrile-water [13,16], $n$-hexane-tert-butyl methyl ether-acetonitrile-water [13,17], $n$-heptane-methyl tert-butyl ether-acetonitrile-water [18], and $n$-hexane-acetonitrile-dichloromethane-water-ethyl acetate [19].

A more advanced method that is derived from LLE is high-speed counter-current chromatography (HSCCC), which is a high-performance liquid-liquid isolation method that lacks solid support resins and shows excellent sample recovery [20]. Therefore, HSCCC is widely used in natural product isolation and purification [21]. In some of our previous reports, this method was successfully applied to the preparative separation of a variety of marine natural products [22-25]. In this study, a new method was developed for efficient purification of baf A1 from S. lohii orf $2 \& 3$ crude extract by applying a three-phase solvent system LLE followed by HSCCC with a two-phase solvent system (n-hexane-acetonitrile-water).

\section{Results}

\subsection{Selection of a Three-Phase Solvent System for Extraction}

The overall experimental design for baf A1 isolation and purification is presented in Figure 1. Among several tested mixed solvent systems (Table 1), a few three-phase systems were observed in the mixtures with ratios ranging from 6:4:5:5 to 8:2:5:5, (n-hexane-ethyl acetate-acetonitrile-water, $v / v / v / v)$. These three-phase mixtures were then tested to determine which could be most optimal to separate soybean oil, baf A1, and hydrophilic impurities by polarity. As shown in Table 1, the solvent system of 7:3:5:5 possessed higher baf A1 recovery in the MP (84.4\%) than that of 8:2:5:5 (82.5\%). Moreover, the solvent system ratio of 6:4:5:5 required much longer settling time, which would be inefficient or problematic in a large-scale process. 


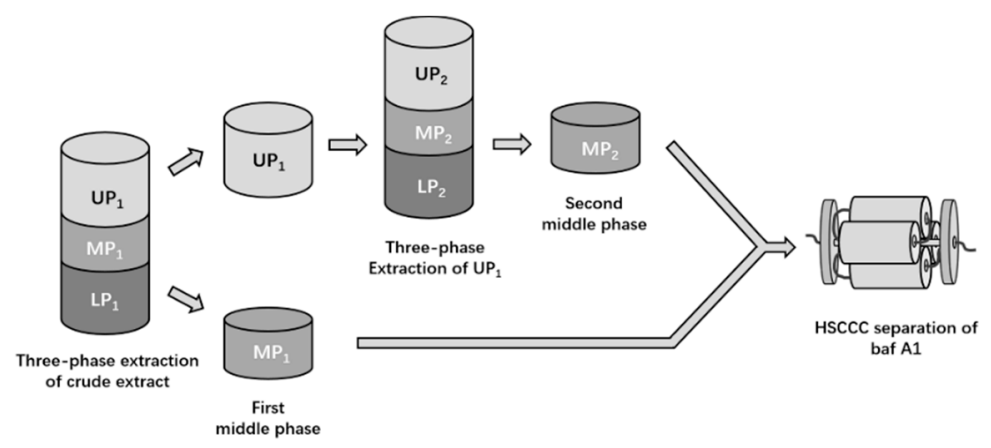

Figure 1. Flowchart of experimental design for baf A1 isolation and purification.

Table 1. Phase partitioning of baf A1 in different three-phase solvent systems ( $n$-hexane-ethyl acetate-acetonitrile-water). UP-upper phase; $\mathrm{MP}$-middle phase; LP-lower phase.

\begin{tabular}{ccccc}
\hline $\begin{array}{c}\text { Volume } \\
\text { Ratio }\end{array}$ & $\begin{array}{c}\text { Phase } \\
\text { Formation }\end{array}$ & $\begin{array}{c}\text { Phase Ratio } \\
\mathbf{( \% )}\end{array}$ & $\begin{array}{c}\text { Baf A1 } \\
\text { Distribution } \\
\text { (UP/MP/LP \%) }\end{array}$ & $\begin{array}{c}\text { System Settling } \\
\text { Time (Second) }\end{array}$ \\
\hline $3: 7: 5: 5$ & 2 & $68.6 / 31.4$ & $/$ & $/$ \\
$5: 5: 5: 5$ & 2 & $67.6 / 32.4$ & $/$ & $/$ \\
$6: 4: 5: 5$ & 3 & $31.4 / 34.3 / 34.3$ & $15.1 / 84.9 / 0$ & $>180$ \\
$7: 3: 5: 5$ & 3 & $38.9 / 25 / 36.1$ & $15.6 / 84.4 / 0$ & 50 \\
$8: 2: 5: 5$ & 3 & $45.7 / 17.1 / 37.2$ & $15.9 / 82.5 / 1.56$ & $<20$ \\
$9: 1: 5: 5$ & 2 & $47.2 / 52.8$ & $/$ & $/$ \\
\hline
\end{tabular}

Next, we measured the distribution of soybean oil in different three-phase solvent systems in which only the solvent and soybean oil (without any crude extract) were mixed. As shown in Table 2, the concentration of oil in the MP of the solvent system of 7:3:5:5 or 8:2:5:5 was very low, demonstrating that over $96 \%$ of oil was removed from this partition. Although the solvent system of 8:2:5:5 showed a slightly better oil elimination effect than that of 7:3:5:5, the latter was selected for baf A1 enrichment due to its slightly higher recovery of baf A1 in the MP (Table 1). After a single extraction of the crude extract, the MP contained $84.4 \%$ of baf A1 and only $0.5 \%$ of the total soybean oil, as calculated from the data in Table 2. After the second repetition of three-phase liquid extraction, a total of $96.4 \%$ of baf A1 was recovered, and $99 \%$ of soybean oil and the majority of polar impurities were removed.

Table 2. Distribution of soybean oil in different solvent systems upon a single extraction of the crude extract.

\begin{tabular}{ccccc}
\hline $\begin{array}{c}\text { Solvent } \\
\text { Systems }\end{array}$ & UP (g) & MP (g) & Control (g) ${ }^{\mathbf{1}}$ & $\begin{array}{c}\text { Total Soybean Oil } \\
\text { Elimination (\%) }\end{array}$ \\
\hline $6: 4: 5: 5$ & 4.41 & 0.11 & 4.67 & $94.43 \%$ \\
$7: 3: 5: 5$ & 3.94 & 0.02 & 4.10 & $96.09 \%$ \\
$8: 2: 5: 5$ & 4.42 & 0.02 & 4.52 & $97.78 \%$ \\
\hline
\end{tabular}

${ }^{1} 5 \mathrm{~mL}$ of soybean oil dried individually.

\subsection{Determination of Partition Coefficient Values $\left(K_{D}\right)$ and HSCCC Separation}

Determining partition coefficient values $\left(\mathrm{K}_{\mathrm{D}}\right)$ is a critical step in planning for HSCCC separation. According to the golden rules reported by Ito [20], an ideal two-phase solvent system should yield a suitable $K_{D}$ value in the range from 0.5 to 2 . In addition, short settling times $(<20 \mathrm{~s})$ and high stationary-phase retention are required for good results in HSCCC.

Accordingly, a number of two-phase solvent systems composed of different ratios of $n$-hexane-acetonitrile-water were evaluated. As shown in Table 3, a smaller ratio of acetonitrile to water led to a larger $K_{D}$ value of baf $A 1$ in an acceptable range, and the solvent system of 15:8:12 was 
ultimately selected. Given the $\mathrm{K}_{\mathrm{D}}$ value of 0.84 , the HSCCC method was established with a flow rate of $3 \mathrm{~mL} / \mathrm{min}$, revolution speed of $900 \mathrm{rpm}$, and $62 \%$ retention rate of stationary phase. Under these conditions, $77.4 \mathrm{mg}$ of purified baf A1 was obtained from a single HSCCC run in under $90 \mathrm{~min}$ using $480.2 \mathrm{mg}$ of three-phase liquid partitioning enriched extract (Figure 2D).

Table 3. Partition coefficient values $\left(\mathrm{K}_{\mathrm{D}}\right)$ of baf $\mathrm{A} 1$ in different solvent systems ( $n$-hexane-acetonitrile water).

\begin{tabular}{ccc}
\hline Volume Ratio & $\mathbf{K}_{\mathbf{D}}$ (MP Extract) & $\begin{array}{c}\text { Volume Ratio } \\
\text { (UP/LP) }\end{array}$ \\
\hline $15: 6: 6$ & 0.06 & $1.2 / 1$ \\
$15: 8: 8$ & 0.08 & $1 / 1$ \\
$15: 10: 10$ & 0.12 & $1 / 1.3$ \\
$15: 9: 11$ & 0.28 & $1.3 / 1$ \\
$15: 8: 12$ & 0.84 & $1.1 / 1$ \\
$15: 7: 13$ & 1.74 & $1 / 1.3$ \\
$15: 6: 14$ & 2.45 & $1 / 1.4$ \\
\hline
\end{tabular}

A
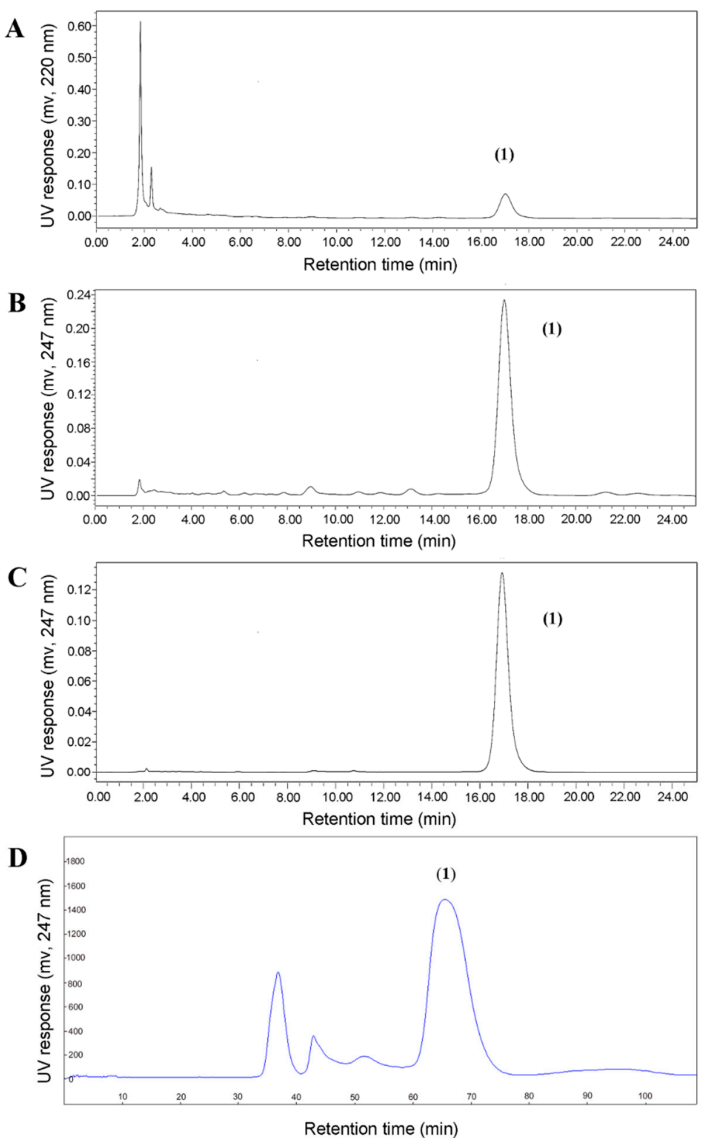

Figure 2. High-performance liquid chromatography (HPLC) chromatograms. (A) A crude extract sample from S. lohii; detection, $220 \mathrm{~nm}$. (B) The same crude extract sample from S. lohii; detection, 247 nm. (C) The high-speed counter-current chromatography (HSCCC) fraction of baf A1; detection, 247 $\mathrm{nm}$. Conditions: column, YMC-Pack $\mathrm{C}_{18}$ column $(150 \times 4.6 \mathrm{~mm}$ inner diameter (ID), $5 \mu \mathrm{m})$; column temperature, $25{ }^{\circ} \mathrm{C}$; mobile phase, methanol and water in the isocratic elution mode (acetonitrile $80 \%, 25 \mathrm{~min}$ ); flow rate, $0.8 \mathrm{~mL} / \mathrm{min}$; detection, $247 \mathrm{~nm}$. (D) A representative HSCCC chromatogram of the enriched sample using $n$-hexane-acetonitrile-water (15:8:12, v/v/v). Conditions: stationary phase, lower phase; flow rate, $3.0 \mathrm{~mL} / \mathrm{min}$; revolution speed, $900 \mathrm{rpm}$; sample amount, $480.2 \mathrm{mg}$; separation temperature, $25^{\circ} \mathrm{C}$; detection wavelength, $247 \mathrm{~nm}$; retention of the stationary phase: $62 \%$. 


\subsection{Structural Identification of baf A1 after HSCCC}

Based on HPLC analysis (Figure 2C), $77.4 \mathrm{mg}$ of baf A1 was isolated with purity $>95 \%$ from 480.2 $\mathrm{mg}$ of the enriched extract sample using HSCCC (Figure 2D). The overall recovery of baf A1 was 95.7\%. The structural identification was carried out using electrospray ionization (ESI)-MS, as well as ${ }^{1} \mathrm{H}-$ and ${ }^{13} \mathrm{C}-\mathrm{NMR}$ (Figures S1 and S2, Supplementary Materials). The results are summarized as follows, which matched literature values for baf A1 and our data obtained from a previous research project [26].

Compound (1) in Figure 2, white powder, ESI-MS $(m / z): 645.26[\mathrm{M}+\mathrm{Na}]^{+},{ }^{1} \mathrm{H}-\mathrm{NMR}(500 \mathrm{MHz}$, $\left.\mathrm{CDCl}_{3}\right) \delta: 6.68(1 \mathrm{H}, \mathrm{s}, \mathrm{H}-3), 6.51((1 \mathrm{H}, \mathrm{dd}, J=15.01,10.63 \mathrm{~Hz}, \mathrm{H}-12), 5.81(1 \mathrm{H}, \mathrm{d}, J=10.66 \mathrm{~Hz}, \mathrm{H}-11)$, $5.77(1 \mathrm{H}, \mathrm{d}, J=9.12 \mathrm{~Hz}, \mathrm{H}-5), 5.54(1 \mathrm{H}, \mathrm{d}, J=1.97 \mathrm{~Hz}, 19-\mathrm{OH}), 5.16(1 \mathrm{H}, \mathrm{dd}, J=15.07,9.34 \mathrm{~Hz}, \mathrm{H}-13)$, $4.95(1 \mathrm{H}, \mathrm{dd}, J=8.68,1.35 \mathrm{~Hz}, \mathrm{H}-15), 4.65(1 \mathrm{H}, \mathrm{d}, J=4.03 \mathrm{~Hz}, 17-\mathrm{OH}), 4.13(1 \mathrm{H}, \mathrm{ddd}, J=10.81,4.21$, $2.03 \mathrm{~Hz}, \mathrm{H}-17), 3.88(1 \mathrm{H}, \mathrm{t}, J=9.00 \mathrm{~Hz}, \mathrm{H}-14), 3.69(1 \mathrm{H}, \mathrm{m}, \mathrm{H}-21), 3.63\left(3 \mathrm{H}, \mathrm{s}, 2-\mathrm{OCH}_{3}\right), 3.49(1 \mathrm{H}, \mathrm{dd}, J=$ 10.24, $2.23 \mathrm{~Hz}, \mathrm{H}-23), 3.29(1 \mathrm{H}, \mathrm{d}, J=6.82 \mathrm{~Hz}, \mathrm{H}-7), 3.24\left(3 \mathrm{H}, \mathrm{s}, 14-\mathrm{OCH}_{3}\right), 2.54(1 \mathrm{H}, \mathrm{m}, \mathrm{H}-6), 2.30(1 \mathrm{H}$, $\mathrm{dd}, J=11.90,4.73 \mathrm{~Hz}, \mathrm{H}-20), 2.15(1 \mathrm{H}, \mathrm{m}, \mathrm{H}-16), 2.13(1 \mathrm{H}, \mathrm{m}, \mathrm{H}-9), 1.99(3 \mathrm{H}, \mathrm{d}, J=1.22 \mathrm{~Hz}, \mathrm{H}-26), 1.95$ $(1 \mathrm{H}, \mathrm{m}, \mathrm{H}-9), 1.94(3 \mathrm{H}, \mathrm{s}, \mathrm{H}-29), 1.90(1 \mathrm{H}, \mathrm{m}, \mathrm{H}-8), 1.86(1 \mathrm{H}, \mathrm{m}, \mathrm{H}-24), 1.77(1 \mathrm{H}, \mathrm{m}, \mathrm{H}-18), 1.62(1 \mathrm{H}, \mathrm{s}$, 7-OH), $1.32(1 \mathrm{H}, \mathrm{m}, \mathrm{H}-22), 1.15(1 \mathrm{H}, \mathrm{td}, J=11.57,2.09 \mathrm{~Hz}, \mathrm{H}-20), 1.07$ (3H, d, J = 7.05, H-27), $1.04(3 \mathrm{H}, \mathrm{d}$, $J=7.19 \mathrm{~Hz}, \mathrm{H}-31), 0.94(3 \mathrm{H}, \mathrm{d}, J=2.90 \mathrm{~Hz}, \mathrm{H}-32), 0.93(3 \mathrm{H}, \mathrm{d}, J=2.83 \mathrm{~Hz}, \mathrm{H}-28), 0.90(3 \mathrm{H}, \mathrm{d}, J=6.86$ $\mathrm{Hz}, \mathrm{H}-25), 0.83$ (3H, d, $J=6.86 \mathrm{~Hz}, \mathrm{H}-30), 0.77(3 \mathrm{H}, \mathrm{d}, J=6.80 \mathrm{~Hz}, \mathrm{H}-33) ;{ }^{13} \mathrm{C}-\mathrm{NMR}\left(125 \mathrm{MHz}, \mathrm{CDCl}_{3}\right)$ ס: 167.5 (C-1), 143.1 (C-10), 142.9 (C-5), 141.4 (C-2), 133.7 (C-3), 133.1 (C-12), 133.1 (C-4), 127.3 (C-13), 125.4 (C-11), 99.0 (C-19), 82.3 (C-14), 81.3 (C-7), 75.9 (C-23), 71.1 (C-21), 70.7 (C-17), $60.1\left(2-\mathrm{OCH}_{3}\right), 55.6$ (14-OCH $\left.{ }_{3}\right), 43.6$ (C-20), 42.2 (C-18), 41.3 (C-9), 41.1 (C-22), 40.1 (C-8), 37.3 (C-37.3), 36.8 (C-36.8), 28.0 (C-24), 21.7 (C-21.7), 21.3 (C-25), 20.3 (C-29), 17.4 (C-27), 14.4 (C-33), 14.1 (C-26), 12.2 (C-32), 9.9 (C-30), $7.2(\mathrm{C}-31)$.

\subsection{Comparison of HSCCC and Semi-Preparative HPLC for the Preparative Separation of baf A1}

The efficiency of HSCCC and HPLC for preparative separation of baf A1 from previous enrichment was assessed. The result presented in Table 4 shows that HSCCC could achieve higher productivity of baf A1 with lower organic solvent consumption compared with semi-preparative HPLC. Furthermore, HSCCC is an affordably scalable method with industrial applications that are much more affordable than preparative HPLC due to associated solid support and instrumental costs.

Table 4. Comparison of HSCCC and semi-preparative HPLC with regard to baf A1 separation.

\begin{tabular}{ccc}
\hline & HSCCC & HPLC \\
\hline Stationary phase & Upper phase & YMC-Pack C 18 column \\
& $n$-hexane-acetonitrile-water & $(250 \times 10 \mathrm{~mm} \mathrm{ID,5 \mu m)}$ \\
Mobile phase & $(15: 8: 12, v / v / v)$ & Acetonitrile-water $(80: 20, v / v)$ \\
Lample capacity per run (mg) & 480 & 5 \\
Run time (min) & 90 & 30 \\
Productivity (mg/min) & 0.81 & 0.03 \\
Purity of isolated compound & $>95 \%$ & $98 \%$ \\
Organic solvent consumption & 2.29 & 68.57 \\
(L/g) & &
\end{tabular}

\section{Discussion}

Oil is often added to the fermentation broths of actinomycetes to enhance the production of polyketide natural products. However, the subsequent extraction of the broth by organic solvent typically results in a crude extract with a high concentration of oil, which is undesirable and introduces significant difficulties in downstream processing and chromatographic steps for the purification of target compounds. This study describes a novel and efficient method for the rapid enrichment and separation of baf A1 from oils and crude extract of marine S. lohii fermentation broth. Compared with classical 
liquid two-phase extractions and column chromatography, this method is based on a three-phase solvent system capable of very efficiently removing residual soybean oil and most other impurities in the crude extract. Furthermore, rapid separation of baf A1 with high yield and purity was achieved from the resulting enriched partition fraction using HSCCC. The results of the present study indicate that liquid-liquid extraction with a three-phase solvent system significantly simplifies the enrichment process of natural products from a complex matrix. It was also demonstrated that HSCCC is a powerful technique for the rapid preparative isolation and purification of natural products, which is in line with many other reports about this technique. The established strategy for enrichment and separation may provide a useful approach to fill the gap between large-scale natural product fermentation and purification for producing the sample supply required for in-depth pharmacological investigations and drug development, which can be applied to baf A1, as well as other target molecules.

\section{Materials and Methods}

\subsection{Reagents and Materials}

All organic solvents used for three-phase LLE and two-phase HSCCC were of analytical grade and purchased from Huadong Chemicals (Hangzhou, China). Chromatographic-grade solvents used for HPLC analyses were purchased from Anpel Laboratory Technologies (Shanghai, China).

\subsection{Crude Extract}

A single colony of $S$. lohii orf $2 \& 3$ was inoculated into $30 \mathrm{~mL}$ of $2 \times$ YT medium at a 1:10 ratio and cultured on shakers at $220 \mathrm{rpm}, 28^{\circ} \mathrm{C}$ for $2 \mathrm{~d}$. Then, $3 \mathrm{~mL}$ of seed culture was transferred into each $30 \mathrm{~mL}$ of fermentation medium ( $20 \mathrm{~g}$ of glucose, $20 \mathrm{~g}$ of soybean flour, $60 \mathrm{~g}$ of soybean oil, $2 \mathrm{~g}$ of NZ-amine, $1.5 \mathrm{~g}$ of corn syrup, $1 \mathrm{~g}$ of yeast extract, $8 \mathrm{~g}$ of $\mathrm{NaNO}_{3}, 8 \mathrm{~g}$ of $\mathrm{CaCO}_{3}, 6 \mathrm{~g}$ of $\left(\mathrm{NH}_{4}\right)_{2} \mathrm{SO}_{4}$, $5 \mathrm{~g}$ of NaCl , and $0.3 \mathrm{~g}$ of $\mathrm{K}_{2} \mathrm{HPO}_{4}$ per liter) at $28^{\circ} \mathrm{C}, 250 \mathrm{rpm}$ for another $7 \mathrm{~d}$. Finally, a total of 10 $\mathrm{L}$ of fermentation culture was collected and extracted with EtOAc, and a crude extract $(4.9 \mathrm{~g})$ was recovered after concentration under vacuum.

\subsection{Apparatus}

HSCCC separation was conducted using a TBE-300C high-speed counter-current chromatograph (Tauto Biotech Co. Ltd., Shanghai, China) equipped with three serially connected polytetrafluoroethylene (PTFE) multi-layer coils (inner diameter (ID) $2.6 \mathrm{~mm}$, total volume $300 \mathrm{~mL}$ ) and a 20-mL sample loop. The separation temperature was adjusted using an HX 1050 constant-temperature circulating implement (Beijing Boyikang Lab Instrument, Beijing, China). An S-1007 constant flow pump (Shenyitong Tech \& Exploitation, Beijing, China) was applied to pump both the stationary and the mobile phases. The outlet effluent was continuously monitored using a C-635 ultraviolet (UV) photometer (Buchi, Flawil, Switzerland). The HSCCC separation data collection and analysis was carried out using N2000 chromatography workstation (Zhejiang University, Hangzhou, China). HPLC analysis was conducted on a Waters Alliance 2695 with a Waters model 2996 diode array detector and was controlled by a Waters Empower System (Waters Co., Milford, MA, USA). A Waters 600 system (Waters, MA, USA) equipped with a 5-mL injection system and a Waters 2996 photodiode array detector were used for semi-preparative isolation.

Compound characterization was performed using a Thermo TSQ Quantum Access spectrometer with an ESI interface (Thermo Fisher Scientific, San Jose, CA, USA) and a Bruker AVANCE-500 NMR spectrometer using standard pulse programs (Bruker, Fällanden, Switzerland).

\subsection{Selection of Three-Phase Solvent System for Extraction}

Small volumes of $n$-hexane, ethyl acetate, acetonitrile, and water were mixed in different ratios to form a 20-mL mixture in a serum bottle, and the volume of each phase was recorded. The crude extract of $S$. lohii orf $2 \& 3$ fermentation culture $(100 \mathrm{mg})$ was dissolved completely in each three-phase solvent 
system at room temperature. The three phases were separated using a glass funnel; then, the MP was concentrated at $40{ }^{\circ} \mathrm{C}$ under reduced pressure to afford the first MP extract $\left(\mathrm{MP}_{1}\right)$. The UP extract $\left(\mathrm{UP}_{1}\right)$ was re-dissolved in a newly prepared three-phase solvent system to produce the second MP extract $\left(\mathrm{MP}_{2}\right)$, which improved recovery of the target compound, baf A1. The two MPs were combined and dried to afford a baf A1-enriched fraction (Figure 1). The concentrations of baf A1 in different phases were analyzed by HPLC.

To analyze the distribution of soybean oil in the three-phase extraction system, $5 \mathrm{~mL}$ of soybean oil was mixed vigorously with a total of $40 \mathrm{~mL}$ of the three-phase solvent system composed of $n$-hexane-ethyl acetate-acetonitrile-water in a separatory funnel at room temperature. Each phase was separated and, after settlement, concentrated under vacuum. The volume and weight of each phase was measured before and after solvent evaporation. As a control, $5 \mathrm{~mL}$ of soybean oil was treated in the same way for partial evaporation and weight measurement. Each test was performed in triplicate.

\subsection{Preparation of Enriched Example}

Firstly, $4.9 \mathrm{~g}$ of crude extract of S. lohii orf2\&3 fermentation was completely dissolved in the selected three-phase solvent system. The first UP was re-extracted with the identical solvent system. The first and second MPs were combined and concentrated, yielding $480.2 \mathrm{mg}$ of a baf A1-enriched fraction.

\subsection{Selection of Partition Coefficient Values $\left(K_{D}\right)$}

Solvent systems composed of $n$-hexane-acetonitrile-water were used for the testing of partition coefficient values $\left(\mathrm{K}_{\mathrm{D}}\right)$. The method used to measure this was as follows: firstly, a small amount $(10 \mathrm{mg})$ of the enriched baf A1 fraction was added into a 2-mL Eppendorf tube containing pre-equilibrated two-phase solvents. The equilibration of target compound between two phases was conducted by shaking thoroughly for $3 \mathrm{~min}$. Each settled phase was then passed through a $0.3-\mu \mathrm{m}$ nylon membrane filter and analyzed by HPLC. The $K_{D}$ values were calculated using the equation $K_{D}=A_{1} / A_{2}$, wherein $A_{1}$ and $A_{2}$ represent the peak areas of target compound in upper and lower phase, respectively.

\subsection{Preparation of the Two-Phase Solvent System and Sample Solution}

In the present study, a two-phase solvent system consisting of $n$-hexane-acetonitrile-water (15:8:12, $v / v / v$ ) was used for the HSCCC isolation. The mixture of this solvent system ( $2 \mathrm{~L}$ in total) was added to a separation funnel and vigorously shaken and equilibrated at room temperature. The two phases were separated and degassed by sonication for 15 min shortly before use. For HSCCC isolation, the sample solution was prepared by dissolving $480.2 \mathrm{mg}$ of enriched baf $\mathrm{A} 1 \mathrm{in} 15 \mathrm{~mL}$ of the pre-equilibrated two-phase solvent system.

\subsection{HSCCC Separation}

In this study, the organic UP of the two-phase solvent system was selected to be the stationary phase and the aqueous LP was selected as the mobile phase. The HSCCC procedure was as follows: the multilayer coiled column was completely filled with the organic UP. Then, the aqueous LP was pumped into the column from head to tail at a flow rate of $3.0 \mathrm{~mL} / \mathrm{min}$, while the column was smoothly rotated at $900 \mathrm{rpm}$. After the hydrodynamic equilibrium of system was established, as indicated by the mobile phase emerging from the column outlet, the prepared sample solution $(15 \mathrm{~mL})$ was manually loaded through the injection valve. The effluent from the column was continuously monitored using a UV detector at the wavelength of $247 \mathrm{~nm}$, and this was collected automatically in 5 min fractions of $15 \mathrm{~mL}$ in individual test tubes. During the HSCCC isolation process, the column temperature was $25^{\circ} \mathrm{C}$. According to the elution UV chromatogram, collected peak fractions were analyzed by HPLC for combination of multiple test tubes or fraction pooling. After separation, the solvent in the column was replaced with nitrogen for protected long-term storage. 
4.9. HPLC Analysis, Semi-Preparative HPLC Purification of baf A1 in Fractions from HSCCC Separation, and Compound Identification by MS and NMR

HPLC analyses of crude sample and HSCCC peak fractions were performed using a Waters Alliance 2695 liquid chromatography system, equipped with a reverse-phase YMC-Pack $C_{18}$ column $\left(150 \times 4.6 \mathrm{~mm}\right.$ ID, $5 \mu \mathrm{m}$, YMC Co. Ltd., Tokyo, Japan) at $25^{\circ} \mathrm{C}$. The purity of baf A1 was determined by ${ }^{1} \mathrm{H}-\mathrm{NMR}$ spectroscopy and an HPLC external standard method. HPLC-purified baf A1 was selected as external standard. For all HPLC analyses, the mobile phase was acetonitrile and water with a flow rate of $0.8 \mathrm{~mL} / \mathrm{min}$ in isocratic elution mode (acetonitrile 80\%, $25 \mathrm{~min}$ ), and the eluent was evaluated by UV detection at $247 \mathrm{~nm}$. A Waters Alliance 2695 liquid chromatography system equipped with a larger YMC-Pack $C_{18}$ column $(250 \times 10 \mathrm{~mm}$ ID, $5 \mu \mathrm{m}$, YMC Co. Ltd., Tokyo, Japan) was used for semi-preparative purification of baf A1 from the previous HSCCC enriched fractions. The flow rate was $2 \mathrm{~mL} / \mathrm{min}$, and acetonitrile and water (acetonitrile $80 \%, 30 \mathrm{~min}$ ) was used as the mobile phase in isocratic elution mode. The wavelength of UV detection and the column temperature were identical to those of the analytical HPLC protocol. The compound identification of baf A1 in HSCCC peak fractions and semi-preparative HPLC fractions was conducted by ESI-MS, as well as ${ }^{1} \mathrm{H}-\mathrm{NMR}$ and ${ }^{13} \mathrm{C}-\mathrm{NMR}$ analyses.

Supplementary Materials: The following are available online at http://www.mdpi.com/1660-3397/18/6/332/s1: Figure S1. ${ }^{1} \mathrm{H}-\mathrm{NMR}\left(500 \mathrm{MHz}, \mathrm{CDCl}_{3}\right)$ spectrum of bafilomycin A1; Figure S2. ${ }^{13} \mathrm{C}-\mathrm{NMR}\left(125 \mathrm{MHz}, \mathrm{CDCl}_{3}\right)$ spectrum of bafilomycin A1.

Author Contributions: Conceptualized and designed the experiments, Y.Y., X.Y., S.L., and S.H.; prepared the fermentation extract, X.Z., Z.L., and X.X.; performed the baf A1 isolation experiments, Y.Y. and X.H.; wrote the paper, Y.Y.; revised the paper, S.H., S.L., T.W., and W.Z. All authors read and agreed to the published version of the manuscript.

Funding: This study was supported by the National Natural Science Foundation of China (41776168, 41906093), the Ningbo Public Service Platform for High-Value Utilization of Marine Biological Resources (NBHY-2017-P2), the National 111 Project of China (D16013), the Li Dak Sum Yip Yio Chin Kenneth Li Marine Biopharmaceutical Development Fund, the K.C. Wong Magna Fund in Ningbo University, the Shandong Provincial Natural Science Foundation (ZR2017BD009), the Program of Weihai Science and Technology Development (2018ZC11), the State Key Laboratory of Microbial Technology Open Projects Fund (M2019-05), and the State Key Laboratory of Natural and Biomimetic Drugs (K20190205).

Acknowledgments: We appreciate C. Benjamin Naman (Ningbo University, China and University of California, San Diego, USA) for critical reading and linguistic editing of the manuscript.

Conflicts of Interest: The authors declare no conflicts of interest.

\section{References}

1. Werner, G.; Hagenmaier, H.; Albert, K.; Kohlshorn, H. The structure of the bafilomycins, a new group of macrolide antibiotics. Tetrahedron Lett. 1983, 24, 5193-5196. [CrossRef]

2. Werner, G.; Hagenmaier, H.; Drautz, H.; Baumgartner, A.; Zähner, H. Metabolic products of microorganisms. 224. Bafilomycins, a new group of macrolide antibiotics. Production, isolation, chemical structure and biological activity. J. Antibiot. 1984, 37, 110-117. [CrossRef] [PubMed]

3. Bowman, E.J.; Siebers, A.; Altendorf, K. Bafilomycins: A class of inhibitors of membrane ATPases from microorganisms, animal cells, and plant cells. Proc. Natl. Acad. Sci. USA 1988, 85, 7972-7976. [CrossRef] [PubMed]

4. Dröse, S.; Altendorf, K. Bafilomycins and concanamycins as inhibitors of V-ATPases and P-ATPases. J. Exp. Biol. 1997, 200, 1-8. [PubMed]

5. Pérez-Sayáns, M.; Somoza-Martín, J.M.; Barros-Angueira, F.; Rey, J.M.; García-García, A. V-ATPase inhibitors and implication in cancer treatment. Cancer Treat. Rev. 2009, 35, 707-713. [CrossRef]

6. Mauvezin, C.; Nagy, G.; Juhász, P.; Neufeld, T.P. Autophagosome-lysosome fusion is independent of V-ATPase-mediated acidification. Nat. Commun. 2015, 6, 7007. [CrossRef]

7. Scheidt, K.A.; Bannister, T.D.; Tasaka, A.; Wendt, M.D.; Savall, B.M.; Fegley, G.J; Roush, W.R. Total Synthesis of (-)-Bafilomycin A 1. J. Am. Chem. Soc. 2002, 124, 6981-6990. [CrossRef] 
8. Toshima, K.; Jyojima, T.; Yamaguchi, H.; Noguchi, Y.; Yoshida, T.; Murase, H.; Nakata, M.; Matsumura, S. Total synthesis of Bafilomycin A(1). J. Org. Chem. 1997, 62, 3271-3284. [CrossRef]

9. Gagliardi, S.; Gatti, P.A.; Belfiore, P.; Zocchetti, A.; Clarke, G.D.; Farina, C. Synthesis and structure-activity relationships of bafilomycin A1 derivatives as inhibitors of vacuolar $\mathrm{H}^{+}$-ATPase. J. Med. Chem. 1998, 41, 1883-1893. [CrossRef]

10. Li, Z.; Du, L.; Zhang, W.; Zhang, X.W.; Jiang, Y.Y.; Liu, K.; Men, P.; Xu, H.F.; Fortman, J.L.; Sherman, D.H.; et al. Complete elucidation of the late steps of bafilomycin biosynthesis in Streptomyces lohii. J. Biol. Chem. 2017, 292, 7095-7104. [CrossRef]

11. Castro, L.D.; Priego-Capote, F. Ultrasound assistance to liquid-liquid extraction: A debatable analytical tool. Anal. Chim. Acta 2007, 583, 2-9. [CrossRef] [PubMed]

12. Greer, D.; Pfahl, L.; Rieck, J.; Daniels, T.; Garza, O. Comparison of a novel distillation method versus a traditional distillation method in a model gin system using liquid/liquid extraction. J. Agric. Food Chem. 2008, 56, 9030-9036. [CrossRef] [PubMed]

13. Shibusawa, Y.; Yamakawa, Y.; Noji, R.; Yanagida, A.; Shindo, H.; Ito, Y. Three-phase solvent systems for comprehensive separation of a wide variety of compounds by high-speed counter-current chromatography. J. Chromatogr. A 2006, 1133, 119-125. [CrossRef] [PubMed]

14. Yin, H.; Zhang, S.; Long, L.J.; Yin, H.; Tian, X.P.; Luo, X.M.; Nan, H.H.; He, S. The separation of flavonoids from Pongamia pinnata using combination columns in high-speed counter-current chromatography with a three-phase solvent system. J. Chromatogr. A 2013, 1315, 80-85. [CrossRef] [PubMed]

15. Wu, X.Y.; Chao, Z.M.; Wang, C.; Yu, L. Separation of chemical constituents from three plant medicines by counter-current chromatography using a three-phase solvent system at a novel ratio. J. Chromatogr. A 2015, 1384, 107-114. [CrossRef] [PubMed]

16. Zou, D.L.; Zhu, X.L.; Zhang, F.; Du, Y.R.; Ma, J.B.; Jiang, R.W. An efficient strategy based on liquid-liquid extraction with three-phase solvent system and high- speed counter-current chromatography for rapid enrichment and separation of epimers of minor bufadienolide from toad meat. J. Agric. Food Chem. 2018, 66, 1008-1014. [CrossRef]

17. Liu, Y.J.; Chen, X.F.; Liu, J.X.; Di, D.L. Three-phase solvent systems for the comprehensive separation of a wide variety of compounds from Dicranostigma leptopodum by high-speed counter-current chromatography. J. Sep. Sci. 2015, 38, 2038-2045. [CrossRef]

18. Hamzaoui, M.; Renault, J.H.; Nuzillard, J.M.; Reynaud, R.; Hubert, J. Stepwise elution of a three-phase solvent system in centrifugal partition extraction: A new strategy for the fractionation and phytochemical screening of a crude bark extract. Phytochem. Anal. 2013, 24, 367-373. [CrossRef]

19. Wang, F.Z.; Li, R.; Long, L.J.; Tian, X.P.; Xiao, Z.H.; Zhang, S.; Yin, H. A three-phase solvent system in high-speed counter-current chromatographic for the separation and purification of bioactive constituents from Acanthus ilicifolius. Chromatographia 2015, 78, 1401-1407. [CrossRef]

20. Ito, Y. Golden rules and pitfalls in selecting optimum conditions for high-speed counter-current chromatography. J. Chromatogr. A 2005, 1065, 145-168. [CrossRef]

21. OuYang, X.K.; Jin, M.C.; He, C.H. Preparative separation of four major alkaloids from medicinal plant of Tripterygium Wilfordii Hook F using high-speed counter-current chromatography. Sep. Purif. Technol. 2007, 56, 319-324. [CrossRef]

22. He, S.; Wang, H.Q.; Yan, X.J.; Zhu, P.; Chen, J.J.; Yang, R. Preparative isolation and purification of macrolactin antibiotics from marine bacterium Bacillus amyloliquefaciens using high-speed counter-current chromatography in stepwise elution mode. J. Chromatogr. A 2013, 1272, 15-19. [CrossRef] [PubMed]

23. Ding, L.J.; He, S.; Yan, X.J. Efficient preparation of pseudoalteromone A from marine Pseudoalteromonas rubra QD1-2 by combination of response surface methodology and high-speed counter-current chromatography: A comparison with high-performance liquid chromatography. Appl. Microbiol. Biot. 2014, 98, 4369-4377. [CrossRef] [PubMed]

24. Gu, B.B.; Zhang, Y.Y.; Ding, L.J.; He, S.; Wu, B.; Dong, J.D.; Zhu, P.; Chen, J.J.; Zhang, J.R.; Yan, X.J. Preparative separation of sulfur-containing diketopiperazines from marine fungus Cladosporium sp. using high-speed counter-current chromatography in stepwise elution mode. Mar. Drugs 2015, 13, 354-365. [CrossRef] [PubMed] 
25. Zhou, P.J.; Luo, Q.J.; Ding, L.J.; Fang, F.; Yuan, Y.; Chen, J.J.; Zhang, J.R.; Jin, H.X.; He, S. Preparative isolation and purification of lignans from Justicia procumbens using high-speed counter-current chromatography in stepwise elution mode. Molecules 2015, 20, 7048-7058. [CrossRef]

26. Baker, G.H.; Brown, P.J.; Dorgan, R.J.J.; Everett, J.R.; Ley, S.V.; Slawin, A.M.Z.; Williams, D.J. A conformational study of bafilomycin A1 by X-ray crystallography and nmr techniques. Tetrahedron Lett. 1987, 28, 5565-5568. [CrossRef]

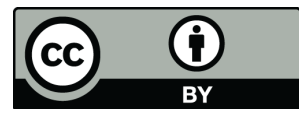

(C) 2020 by the authors. Licensee MDPI, Basel, Switzerland. This article is an open access article distributed under the terms and conditions of the Creative Commons Attribution (CC BY) license (http://creativecommons.org/licenses/by/4.0/). 